\title{
e-interview
}

columns

\section{Richard Warner}

Richard Warner is Professor of Psychiatry, University of Colorado, Director, Colorado Recovery, and formerly Medical Director of the Mental Health Center of Boulder County, USA. He trained at King's College Hospital, London, Littlemore Hospital, Oxford, and Dingleton Hospital, Roxburghshire, UK. His special interests include social and economic factors influencing the development of, and outcome from, mental disorder and the development of effective community treatment and rehabilitation programmes.

If you were not a psychiatrist, what would you do?

Right now? Study history.

What has been the greatest impact of your profession on you personally? It has provided me with opportunities for innovation and a sense of helping people.

Do you feel stigmatised by your profession?

Hell, no!

What are your interests outside of work?

Running, cooking, travel, languages, culture, theatre.

What values do you live by? Loyalty, truthfulness, and helping people.

Who was your most influential trainer, and why?

Ben Pomryn, Consultant Psychiatrist at Littlemore Hospital, Oxford, who introduced me to the power of the therapeutic community.

What job gave you the most useful training experience?

Littlemore Hospital, Oxford, where half of the hospital was operated as a series of therapeutic communities.

Which publication has influenced you most?

The data from Loren Mosher's Soteria Project in California, in the late 1970s, demonstrating that medication is not essential for good outcome in early

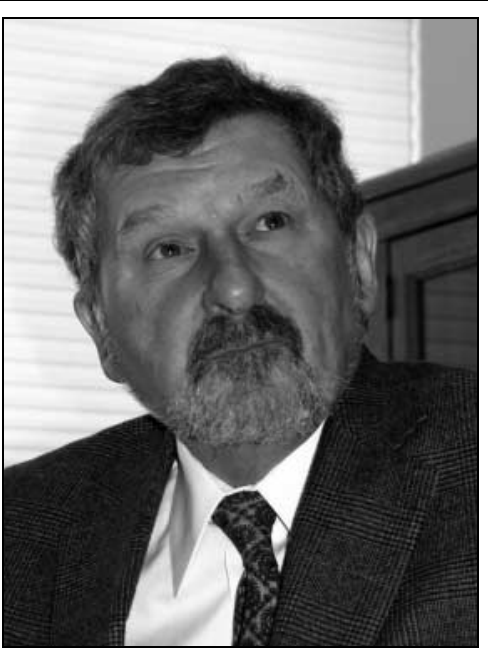

psychosis, pulled me up short and sent me scurrying to study the research on outcome from schizophrenia throughout the 20th century.

How has the political environment influenced your work?

The unholy political alliance between the right and the left in the USA of the 1960s, which led to the hasty deinstitutionalisation of people with serious mental illness and their eventual abandonment in the community, revealed to me that a wholesome movement (in this case, community treatment) can be transformed into its opposite, without the transformation being apparent until it is too late.

What part of your work gives you the most satisfaction?

Creating effective treatment and rehabilitation programmes.

What do you least enjoy?

The day-to-day management of programmes, once created.

What is the most promising opportunity facing the profession? Partnerships between psychiatry and other social and health agencies to create costeffective solutions to social problems (such as child abuse and jail overcrowding).
What is the greatest threat?

Fads, like multiple personality disorder, childhood bipolar disorder, and the next one along.

What single change would substantially improve quality of care? Training psychiatrists more broadly in psychosocial rehabilitation.

What conflict of interest do you encounter most often?

Psychiatrists allowing pharmaceutical representatives to be their most usual source of in-service education.

What is the most important advice you could offer to a new trainee? If you can't say 'No' to a patient when needed, don't become a psychiatrist.

Do you think psychiatry is brainless or mindless?

Neither. It often fails to grasp the importance of the social context of the person.

What is the role of the psychiatrist in rebuilding healthcare systems? Vital, but not automatic. The psychiatrist must earn this role by demonstrating an understanding of systems.

What single change to mental health legislation would you like to see? In the USA, the provision of universal healthcare coverage (which is feasible) and the creation of a national system of care (which is an impossible dream).

What single area of psychiatric practice is most in need of development?

Psychosocial rehabilitation.

What single area of psychiatric research should be given priority? Removing disincentives to employment in national disability pension systems.

How would you like to be remembered?

As someone who helped create programmes that expanded people's lives.

Dominic Fannon

doi: 10.1192/pb.bp.109.025791 